\title{
Brief Communication \\ Assessment of COVID severity by measuring D-dimer and Serum Ferritin level in selected Tertiary Care Hospitals of Dhaka city \\ Afrin $\mathrm{SF}^{1}$, Rahman $\mathrm{MH}^{2}$, AKA Mahmood ${ }^{3}$, Salma $\mathrm{N}^{4}$, Khatun $\mathrm{S}^{5}$
}

\begin{abstract}
Aim: This study was aimed to evaluate the association between serumD-dimer, serum Ferritin with disease severity in patents havingCOVID-19.Methods:Total 80 confirmed COVID-19 patients were enrolled in this cross sectional study. Samples were assessed by positive SARSCoV-2 by RT-PCR testing and were collected from two tertiary Hospitals(IbnSina Medical College Hospital and Ibrahim Cardiac Hospital and Research Institute).We also performed CT findings of COVID patients with or without pulmonary involvement. COVIDpositive patients were divided into two groups (Group 1 and Group2) according to lungs involvement confirmed by CT-scan. In this analysis, several variables such as gender, age, D-dimer and serum ferritin were taken.Results: The Mean of D-dimer in Group-1 subjects was $4.26 \pm 3.60 \mathrm{mg} / \mathrm{L}$ and in Group-2, this was $0.59 \pm 1.08 \mathrm{mg} / \mathrm{L}$. So D-dimer level was significantly raised in COVIDpneumonic patient $(\mathrm{P}$ value $=<0.001)$. The mean of ferritin $(554.65 \pm 515.841) \mathrm{ng} / \mathrm{ml}$ for pneumonic patient was also highly significant than the mean $(133.70 \pm 109.22) \mathrm{ng} / \mathrm{ml}$ of COVID without pneumonia. Conclusion:D-dimer and S. ferritin were elevated in patients with COVID-19. These two reliable biomarkers are correlate with the disease severity and useful for better management of COVIDpositive patients.
\end{abstract}

Keywords: D-Dimer; Serum Ferritin; COVID-19 Patients; SARS-CoV 2

Bangladesh Journal of Medical Science, Special Issue on COVID-19. 2021. Page : 166-170 DOI: https://doi.org/10.3329/bjms.v20i5.55409

\section{Introduction}

For the last one and half year the entire World is experiencing the emergence and devastation caused by COVID-19. The clinical picture of patients with COVID-19 has a pattern of respiratory dominance and depends on the tropism of the virus towards the target organs of the body, because COVID-19 virus uses the ACE-2 receptor for its entry into the host cell. The virus binds ACE-2 with an affinity 1020 times greater than SARS-CoV. This receptor is highly expressed in multiple body tissues, including lung, gastrointestinal, kidney and cardiac tissue, explaining the symptoms present in the prodrome of the disease ${ }^{1}$. Usually in mild COVID, lung is not involved whereas in severe COVIDpatient develops ARDS. It is now universally acknowledged that severe COVID-19 cases have higher mortality than mild cases because severe cases are more likely to suffer ARDS, septic shock, or metabolic acidosis ${ }^{2}$. So it is necessary to distinguish between severe and mild patients at an early stage. According to a report by Yong $\mathrm{Gao}^{3}$, D-dimer can be measured to estimate the severity of COVID-19 and help to diagnose severe COVID-19 patients earlier.

1. Dr. SyedaFahmida Afrin, Professor(cc), Department of Biochemistry, Ibn Sina Medical College, Dhaka.

2. Dr. Md. HasanurRahman, Associate Professor, Department of Cardiology, Ibrahim Cardiac Hospital and Research Institute, Dhaka.

3. Dr. Abu Kholdun Al-Mahmood, Professor, Department of Biochemistry, Ibn Sina Medical College, Dhaka.ORCID ID : https://orcid.org.0000-0002-5474-4481, SCOPUS ID : 12809783500, ResearchGate ID : 2027055323

4. Dr. Salma Nasir, M Phil student, Department of Biochemistry, BIRDEM. Dhaka.

5. Dr. SiddiKaKhatun, AssistantProfessor(cc), Department of Biochemistry, Ibn Sina Medical College, Dhaka.

Correspondence: Dr. SyedaFahmida Afrin, Professor(cc), Department of Biochemistry, Ibn Sina Medical College, Dhaka. Email: drfahmida77@gmail.com 
D-dimer is a byproduct of fibrin degradation. It is widely recognized as a biomarker for thromboembolism and as a prognostic marker for critical patients. COVID-19 being a procoagulant state thus D-dimer has been studied as a biomarker for predicting disease severity. The test shows the presence of clots in the body when COVID becomes serious. Lots of clots in the bodyare formed, especiallyin the lung, because of which the lungs cannot breathe. The blood flow is hampered due to clotting. So, the body tries to break down these clots. D-dimer is detectable for up to eight hours after formation until the time the kidney clears it out. A higher level of D-dimer in the body showed that there is a lot of clot presence in the body which can be a dangerous sign when affected with COVID. So we use D-Dimer to assess for severity of COVID disease and if the patient is going to need oxygen in the future, because the higher their D-dimer, higher is the number of clots in the lungs and the higher the chances that they will need oxygen ${ }^{4}$.

Serum Ferritin is also an important biomarker to assess the severity of COVID patient. The massive release of pro-infammatory mediators and the aberrant activation of the immune and coagulation systems, resembles the so-called cytokine release syndrome, a group of conditions sharing the same pathogenic mechanism, although with a different aetiology 5 . This cytokine storm accounts for the two main causes of mortality in COVID-19, ARDS and secondary haemophagocyticlymphohistiocytosis, the latter occurring in a small subset of patients ${ }^{5}$. Furthermore, since increased levels of ferritin along with a cytokine storm have been described in patients with severe COVID-19, it has been speculated that COVID-19 may be included in the spectrum of the hyperferritinemic syndromes ${ }^{6}$.

\section{Materials and Methods}

This cross sectional study started in May 2020 and continued until December 2020. Within this period samples were assessed by positive SARS-CoV-2 by real-time reverse transcription polymerase chain reaction (RT-PCR) assay and were collected from two tertiary Hospitals(IbnSina Medical College Hospital andIbrahim Cardiac Hospital and Research Institute). All patients underwent HR-CT scan of chest.Depending on CT Scan report, the COVID-19 patients were divided into two groups regarding the presence or absence of lung involvement. Patients were divided into two groups; in Group-1, COVIDpatient with lung involvement and in
Group-2, COVID without lung involvement.In this analysis, several variables such as gender, age, D-dimer and serum ferritin were taken into account.

Laboratory testing Determination of D- dimer and ferritin: Both of D-dimer and ferritin level estimation were carried by ADVIA Centaur XPT/ VITROS Eci. Reference range areless than $0.5 \mathrm{mg} / \mathrm{L}$ for D-dimer and $22-322 \mathrm{ng} / \mathrm{ml}$ for ferritin.

Exclusion criteria: D-dimer has low specificity as there are many other conditions with ongoing activation of the hemostatic system in which D-dimer can be elevated such pregnancy, inflammation, malignancy, trauma, liver disease (decreased clearance), heart disease, sepsis or as a result of hemodialysis, CPR or recent surgery, so patient with these conditions were excluded from this study.

Statistical Analysis: Data were analyzed using SPSS statistical software, version 22.0 (SPSS). All continuous data are presented as means and standard deviations, while categorical data are presented as numbers and percentages. Their difference was compared by independent student's t-test. A chi-square test was used to compare categorical variables. The relationship among biomarkers was assessed using Pearson correlation coefficient test and Multiple Logistic Regression test. Statistical tests were considered significant at the level of $\leq 5 \%$ and considered as test of significant when $\mathrm{p}<0.05$.

Ethical consideration: Prior to commencement of the study, this research was approved by the InstitutionalEthical ReviewBoard(IERB) of Ibnsina Medical College and Ibrahim Cardiac Hospital and Research Institute.Strict confidentiality was maintained regarding the information of the patients during and after the study.

Result: The study population included 40 COVID-19 patients with lung involvement and 40 COVID-19 patients without lung involvement. The mean age of group- 1 and group- 2 were $63.10 \pm 11.45$ years and $53.78 \pm 14.15$ years respectively. $60 \%$ patients were male and $40 \%$ were female. In Group- $1,75 \%$ male and $25 \%$ female and in Group-2, 55\% male and $45 \%$ female was affected.Table-1

Our results showed that majority of male persons were affected by corona virus. The resultwasshowed the comparison of D-dimer levels between people with lung involvement and people without lung involvement. In Table II showed thatin Group-1, the Meanof D-dimer was $4.26 \pm 3.60 \mathrm{mg} / \mathrm{L}$ and in $\mathrm{In}$ Figure-1, was showeda positive correlation between 
Table I: Comparison of Age and Gender between two Groups

\begin{tabular}{|c|c|c|}
\hline Variables & $\begin{array}{c}\text { Group: 1 } \\
\text { Covid with Lung } \\
\text { involvement }\end{array}$ & $\begin{array}{c}\text { Group : 2 } \\
\text { Covid without Lung } \\
\text { involvement }\end{array}$ \\
\hline $\begin{array}{c}\text { Age } \\
\text { (in Years) }\end{array}$ & $63.10 \pm 11.45$ & $53.78 \pm 14.15$ \\
\hline Male & $30(75 \%)$ & $18(45 \%)$ \\
Gender & $10(25 \%)$ & $22(55 \%)$ \\
Female & & \\
\hline
\end{tabular}

Statistical analysis was done by independent sample t-test and Frequency distribution. Results are expressed as (mean $\pm \mathrm{SD})$ and number (n) and percentage $(\%)$.

Our results showed that majority of male persons were affected by corona virus. The resultwasshowed the comparison of D-dimer levels between people with lung involvement and people without lung involvement. In Table II showed thatin Group-1, the Meanof D-dimer was $4.26 \pm 3.60 \mathrm{mg} / \mathrm{L}$ and in Group-2, this was $0.59 \pm 1.08 \mathrm{mg} / \mathrm{L}$. So D-dimer level was significantly raised in COVID pneumonic patient $(\mathrm{P}$ value $=<0.001)$.

\section{Table II: Comparison of D- dimer with both} groups

\begin{tabular}{|c|c|c|c|}
\hline Variables & $\begin{array}{c}\text { Group: 1 } \\
\text { Covid } \\
\text { with Lung } \\
\text { involvement } \\
\text { Mean } \pm \text { SD }\end{array}$ & $\begin{array}{c}\text { Group: } 2 \\
\text { Covid } \\
\text { without Lung } \\
\text { involvement } \\
\text { Mean } \pm \text { SD }\end{array}$ & P- value \\
\hline $\begin{array}{c}\text { D-dimer } \\
\mathrm{mg} / \mathrm{L}\end{array}$ & $4.26 \pm 3.60$ & $.59 \pm 1.08$ & $<0.001^{* * *}$ \\
\hline
\end{tabular}

Statistical analysis was done by independent sample t-test .Results are expressed as (mean $\pm \mathrm{SD})$,

${ }^{* * *} p<0.001, * * p<0.01, * p<0.05$ was taken as the level of significance.

According to table III,the mean of S. Ferritin (554.65 \pm 515.841$) \mathrm{ng} / \mathrm{ml}$ for pneumonic patient was highly significant than the mean(133.70 \pm 109.22$) \mathrm{ng} / \mathrm{ml}$ of COVID without pneumonia.

Table III: Comparison of S. Feritin with both groups

\begin{tabular}{|c|c|c|c|}
\hline Variables & $\begin{array}{c}\text { Group: } 1 \\
\text { Covid with Lung } \\
\text { involvement } \\
\text { Mean } \pm \text { SD }\end{array}$ & $\begin{array}{c}\text { Group: } 2 \\
\text { Covid } \\
\text { without Lung } \\
\text { involvement } \\
\text { Mean } \pm \text { SD }\end{array}$ & P- value \\
\hline $\begin{array}{c}\text { S. Feritin } \\
\text { Ng/ml }\end{array}$ & $\mathbf{5 5 4 . 6 5} \pm \mathbf{5 1 5 . 8 4 1}$ & $\mathbf{1 3 3 . 7 0} \pm \mathbf{1 0 9 . 2 2}$ & $<0.001 * * *$ \\
\hline
\end{tabular}

Statistical analysis was done by independent sample t-test .Results are expressed as (mean $\pm \mathrm{SD}$ ),

${ }^{* * *} p<0.001, * * p<0.01, * p<0.05$ was taken as the level of significance.

Table IV showed significant positive association of COVID with lung involvement with D-dimer $(<0.001)$ and S.Feritin $(<0.05)$. So D-dimer and S.Feritin can be said independently associated with COVID with lung involvement.

\section{Table: IV Association of COVID with lung involvement with different variables}

\begin{tabular}{|c|c|c|c|}
\hline Variables & Beta & p-value & $\begin{array}{c}95.0 \% \text { Confidence } \\
\text { Interval }\end{array}$ \\
\hline D-dimer (mg/L) & 1.172 & $0.000^{* * *}$ & $(1.774,5.875)$ \\
\hline S.Feritin (ng/ml) & .006 & $0.017^{*}$ & $(1.001,1.010)$ \\
\hline
\end{tabular}

Analysis was done by multiple logistic regression.

Beta for standardized regression coefficient $*=$ significant, $* \mathrm{p}<0.05,{ }^{*} \mathrm{p}<0.01, * * * \mathrm{p}<0.001$.

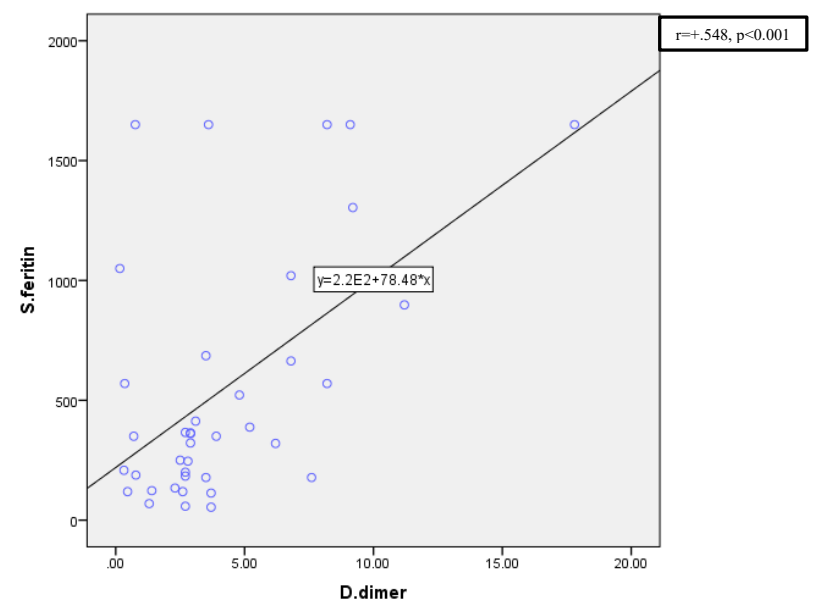

S, Ferritin and D-dimer with Group-1 by using Pearson correlation coefficient.

\section{Discussion:}

This study was done on Mild and severely ill patients with COVID-19 infection. Results showed a significant relation with D-dimer and S.ferritin levels with Pneumonia in COVID positive patients. D-dimer levels were significantly higher in the group with Pneumonia as compared to the group without Pneumonia.Several studies showed strong association between COVID Pneumonia and D-dimer level. We found that an elevated D-dimer was associated with an increased composite poor outcome, especially mortality and severe COVID-19. This finding supports the hypothesis that severe acute respiratory syndrome coronavirus 2 (SARS-CoV-2) infection 
could induce the dysfunction of the hemostatic system, leading to a hypercoagulable state, a condition which we commonly encounter in sepsis ${ }^{7,8}$. Recent evidence of lung pathology dissection has shown occlusion and micro-thrombosis formation in pulmonary small vessels of patients critically ill with COVID-199. However, the etiology of elevated serum D-dimer level is multifactorial and the optimal cutoff value of elevated D-dimer in patients with COVID-19 remains to be established. It is clear that COVID-19associated coagulopathy warrants distinct emphasis and special treatment. According to the International Society of Thrombosis and Hemostasis (ISTH) guideline, a markedly elevated serum D-dimer level (which is still poorly defined as a three- to four-fold increase) implies an increased thrombin production. Patients with COVID-19 with markedly elevated D-dimer levels may require hospitalization, despite the severity of clinical presentation ${ }^{10}$.Another study also support my research,D-dimer is a fibrin degradation product used to exclude the diagnosis of thrombosis. Increased D-dimer levels have been observed in severe Covid-19 cases accompanied by microangiopathy and a hypercoagulable state ${ }^{11}$. Thepresent study was evaluated that $\mathrm{S}$. ferritin is one of important biomarker for COVIDpositive patients. It also detects severity of corona infection. Our study revealed that $\mathrm{S}$. ferritin was raisedsignificantly in severe infection and several similar studies described this association. A study was involving 20 patients with Covid-19 evaluated ferritin, and reported increased serum ferritin levels in patients with severe and very severe Covid-19, with the levels being significantly higher in the very severe group ${ }^{12}$. Another study involving 69 patients with severe Covid-19 reported significantly higher ferritin levels in patients with severe disease than in those with non-severe disease ${ }^{13}$.

Limitation: This study has some limitations. First, for severity analysis, only 80 patients with SARS-
CoV-2 was included which were not sufficient number to elicit the research goal. This was due to detailed patient information, particularly regarding clinical outcomes, was unavailable in the hospital data set. Second, other important biomarkers were not assessed to evaluate the severity. Thirdly, previous similar type of study could affect the analysis and any possible biased results. Another limitation, this study was done in only tertiary hospital, not grass root level, so real scenario is not visualized. However, this is the first preliminary analysis investigating the relationof D-dimer and S. ferritin severity in patients with SARS-CoV-2.

Conclusion: Our Study revealed that D-dimer and ferritin levels are associated with severe pulmonary involvement as detected by CT scan. These two biomarkers are good indicator to assess the severity in patients with SARS-CoV-2. Abnormal level of D-dimer and S. ferritin suggest that early anticoagulant and antiviral therapy might be needed and useful for reduction of morbidity and mortality in COVID positive patients.

Recommendations: For better clinical services and patient care all important biomarkers should be studied in view of their prognostic value in the treatment of COVID-19 and COVID associated symptoms.

Conflict of interest: None declared

Author's contribution:

Data gathering and idea owner of this study:Afrin SF, Salma N

Study design:Afrin SF,Rahman MH

Data gathering and Analysis:Afrin SF,Rahman MH, AKA Mahmood, Salma N,

Writing and submitting manuscript: Afrin SF, Salma N, Khatun S

Editing and approval of final draft: Afrin SF,Rahman MH, AKA Mahmood 


\section{Reference}

1. Thomas J. A Short Note on COVID-19. ARCHIVOS DE MEDICINA 2020;16(5):4

2. Kenneson A, Cannon MJ. Review and meta-analysis of the epidemiology of congenital cytomegalovirus (CMV) infection. Rev Med Virol 2007; 17:253-76.

3. Gao Y, Li T, Han M, Li X, Wu D, Xu Y, et al. . Diagnostic utility of clinical laboratory data determinations for patients with the severe COVID-19. J Med Virol 2020;92:791-6. 10.1002/jmv.2577.

4. LifestyleDesk. 2021. What is the D-Dimer test recommended for coronavirus patients? Available at:https://indianexpress.com/article/lifestyle/health/ddimer-covid-19-patient-test-lungs-oxygen-bloodclots-7309125/Accessed July 30, 2021.

5. Mehta, P., McAuley, D. F., \& Brown, M., et al. HLH AcrossSpeciality Collaboration, UK. COVID-19: consider cytokine storm syndromes and immunosuppression.Lancet. 2020; 395(10229), 10331034.

6. Alunno, A., Carubbi, F. \& Rodriguez-Carrio, J. Storm, typhoon, cyclone or hurricane in patients with COVID-19? Beware of the same storm that has a diferent origin. RMD Open.2020; 6(1), e001295.

7. Peckham H, Gruijter NM, et al. Male sex identified by global COVID-19 meta-analysis as a risk factor for death and ITU admission. Nature Communications2020; 11

8. Levi M, van der Poll T. Coagulation and sepsis. Thromb Res 2017; 149: 38-44.

9. Lin $\mathrm{L}, \mathrm{Lu} \mathrm{L}, \mathrm{Cao} \mathrm{W}$, et al. Hypothesis for potential pathogenesis of SARS-CoV-2 infection - a review of immune changes in patients with viral pneumonia. Emerg Microbes Infect 2020; 1-14.

10. Lue W, Yu H, Gou J, et al. Clinical pathology of critical patient with novel coronavirus pneumonia (COVID-19). Preprints 2020; 1-18.

11. Thachil J, Tang N, Gando S, et al. ISTH interim guidance on recognition and management of coagulopathy in COVID-19. J ThrombHaemost 2020; 1023-1026.

12. Yao Y, Cao J, Wang Q, Shi Q, Liu K, Luo Z et al. D-dimer as a biomarker for disease severity and mortality in COVID-19 patients: a case control study. J Intensive Care 2020;8:49.

13. Zhou B, She J, Wang Y, Ma X. Utility of Ferritin, Procalcitonin, and C-reactive Protein in Severe Patients with 2019 Novel Coronavirus Disease. In: 10.21203/ rs.3.rs-18079/v1 [22 May 2020]

14. Liu T, Zhang J, Yang Y, Ma H, Li Z, Zhang J et al. The role of interleukin-6 in monitoring severe case of coronavirus disease 2019. EMBO Mol Med 2020;12:e12421. 